\title{
Multiparametric observation and analysis of the sea
}

\author{
Aida Alvera-Azcárate · Pierre-Marie Poulain
}

Received: 11 August 2011 / Accepted: 18 August 2011 / Published online: 2 October 2011

(C) Springer-Verlag 2011

The 42nd International Liège Colloquium, which was held in Liège (Belgium) from 26 to 30 April 2010 (Fig. 1), focused on the multiparametric observation and analysis of the ocean, with a particular interest in the development and use of new sensors and platforms for the measurement of oceanic properties. Recent technical and scientific developments have led to a new array of possibilities for measuring the ocean physical, chemical, geological and biological variables and processes, with high precision and spatio-temporal resolution.

The autonomous systems present an advantage over manned systems, as measurements are now routinely taken in places, times and at frequencies which were not feasible before. The flexibility of operation of these observational systems makes them very adequate for adaptive sampling strategies, driven by requirements of numerical models (e.g., for the assimilation of those data in zones with large model errors). In general, the variety of new platforms and sensors used allows

Responsible Editor: Jörg-Olaf Wolff

A. Alvera-Azcárate $(\varangle)$

AGO-GHER-MARE, University of Liège,

Allée du Six Aout, 17, Sart Tilman, Liège, 4000, Belgium

e-mail: a.alvera@ulg.ac.be

A. Alvera-Azcárate

National Fund for Scientific Research,

FNRS-FRS, Brussels, Belgium

\section{P.-M. Poulain}

Istituto Nazionale di Oceanografia, e di Geofisica

Sperimentale (OGS), Borgo Grotta Gigante,

42/c, 34010 Sgonico (Trieste), Italy for more detailed data validation, intercalibration and intercomparison, which in turn lead to a better understanding of the ocean environment. The large variety of topics covered during the Liège Colloquium is reflected in the 17 papers published in this special issue.

Several papers in the special issue describe recent efforts in the monitoring of estuaries, regarding physical and biochemical variables (Garel and Ferreira 2011; Navarro et al. 2011) and geomorphology aspects (Vousdoukas et al. 2011). Estuaries are a challenging environment for automated measuring stations because of their specific characteristics (strong tidal dynamics, large changes in salinity, high turbidity and high sediment dynamics), and these papers serve as a demonstration on the capabilities that are nowadays available to set up a successful monitoring program in an estuary. Also dealing with sediment dynamics, Baeye et al. (2011) discuss the sensor needed to measure turbidity depending on the type of sediment being measured.

Three papers deal with the development of new sensors and sampling methodologies: Abi Kaed Bey et al. (2011) present a new sensor for the measurement of ammonium in oligotrophic waters, which is tested in the northeastern Atlantic Ocean. Daniel et al. (2011) describe a new glider attached to a surface float that uses wave energy to provide forward thrust to the glider. Finally, Ostrovskii (2011) present an autonomous profiler which is fixed on a mooring line, and which allows for multiparametric, high temporal resolution measurements. This profiler is tested in the Black Sea.

Although most of the works presented in this special issue deal with in situ data, two papers address the comparison between satellite and in situ measurements: 


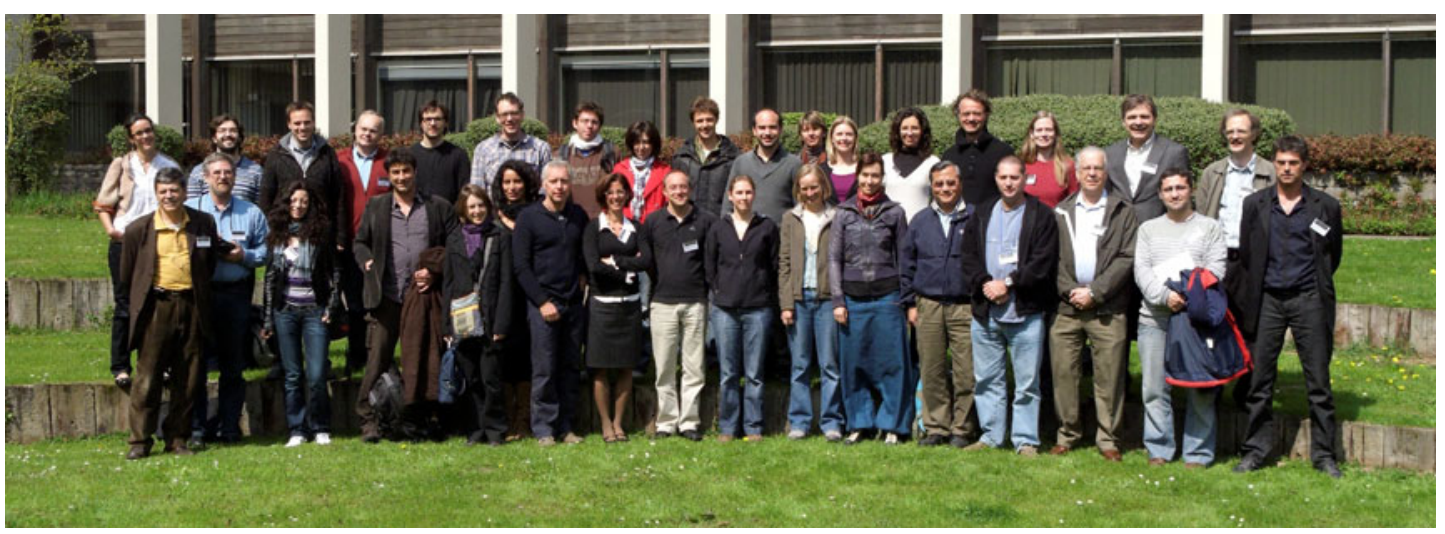

Fig. 1 Participants of the 42nd International Liège Colloquium

Nechad et al. (2011) assess the quality of remotelysensed total suspended matter of the North Sea by comparing them to in situ data from autonomous platforms, while Alvera-Azcárate et al. (2011) performs a comparison between remotely-sensed sea surface temperature and in situ temperature in the western Mediterranean Sea. This comparison is made separately for several in situ sensor types, in order to assess the differences between them and the satellite data.

The use of ships of opportunity allows to record valuable data on a regular basis and at a very high temporal resolution when using the Ferry Box system. Petersen et al. (2011) discuss the advantages and disadvantages of such a system for its use as a water quality monitoring tool, measuring physical, biological and chemical parameters in the North Sea. Combining ship of opportunity data with moored in situ data, Lips et al. (2011) study the phytoplankton dynamics and their relation with the physical, chemical and biological processes in the Gulf of Finland (Baltic Sea).

A special mention is also made of a technology that, although not new, is becoming more and more widespread in oceanographic research and monitoring activities: high-frequency radar measuring surface currents. Five papers in this special issue use highfrequency radar for various purposes: three of them use a combination of radar data and hydrodynamic modelling to study the spatio-temporal variability of the German Bight (Port et al. 2011), the Gulf of Lions (Schaeffer et al. 2011) and the Gulf of Naples (Uttieri et al. 2011). Barth et al. (2011) assimilate radar data into a hydrodynamical model of the German Bight, allowing for the improvement of the wind field used to force the hydrodynamical model. Finally, the work by Gurgel et al. (2011) introduces the use of radar data to detect tsunami waves approaching the coast.
Finally there is one paper (Chu 2011) on novel statistical analyses of worldwide temperature and salinity data (EOF, composite analysis, etc.) as related to global climatic variations.

Other topics covered during the colloquium included the use of Argo profiling floats, drifters, gliders and deep-ocean observatories, among others. New technologies are being constantly developed to match our need for high quality data, and the use of autonomous platforms is becoming more widespread because of the unique advantages they offer in terms of spatial and temporal coverage, and their reduced cost compared with manned systems. Thanks to these systems there is an increasingly homogeneous coverage of the global ocean, but at the same time there is also an enhanced monitoring of regions of particular interest. All these advancements and the associated research that will be realised in the years to come will be certainly revisited in a future edition of the Liège Colloquium.

Acknowledgements The 42nd International Liège Colloquium was supported by the Department of the Navy Grant N6290910-1-1058 issued by the Office of Naval Research Global, the National Science Foundation of Belgium (F.R.S.-FNRS), the Belgian Ministry of Employment and the University of Liège. On behalf of the Scientific Committee and of the Organizing Committee, we thank them for their valuable support.

\section{References}

Abi Kaed Bey SK, Connelly DP, Legiret FE, Harris AJK, Mowlem MC (2011) A high-resolution analyser for the measurement of ammonium in oligotrophic seawater. Ocean Dyn. doi:10.1007/s10236-011-0469-5

Alvera-Azcárate A, Troupin C, Barth A, Beckers JM (2011) Comparison between satellite and in situ sea surface temperature data in the Western Mediterranean Sea. Ocean Dyn 61(6):767-778. doi:10.1007/s10236-011-0403-x 
Baeye M, Fettweis M, Voulgaris G, Lancker VV (2011) Sediment mobility in response to tidal and wind-driven flows along the Belgian inner shelf, southern North Sea. Ocean Dyn 61(5):611-622. doi:10.1007/s10236-010-0370-7

Barth A, Alvera-Azcárate A, Beckers JM, Staneva J (2011) Correcting surface winds by assimilating High-Frequency Radar surface currents in the German Bight. Ocean Dyn 61(5): 599-610. doi:10.1007/s10236-010-0369-0

Chu PC (2011) Global upper ocean heat content and climate variability. Ocean Dyn 61(8):1189-1204. doi:10.1007/s10236011-0411-x

Daniel T, Manley J, Trenaman N (2011) The wave glider: enabling a new approach to persistent ocean observation and research. Ocean Dyn. doi:10.1007/s10236-011-0408-5

Garel E, Ferreira O (2011) Monitoring estuaries using nonpermanent stations: practical aspects and data examples. Ocean Dyn 61(7):891-902. doi:10.1007/s10236-011-0417-4

Gurgel KW, Dzvonkovskaya A, Pohlmann T, Schlick T, Gill E (2011) Simulation and detection of tsunami signatures in ocean surface currents measured by HF radar. Ocean Dyn. doi:10.1007/s10236-011-0420-9

Lips U, Lips I, Liblik T, Kikas V, Altoja K, Buhhalko N, Rünk N (2011) Vertical dynamics of summer phytoplankton in a stratified estuary (Gulf of Finland, Baltic Sea). Ocean Dyn 61(7):903-915. doi:10.1007/s10236-0110421-8

Navarro G, Gutiérrez FJ, Díez-Minguito M, Losada MA, Ruiz J (2011) Temporal and spatial variability in the Guadalquivir estuary: a challenge for real-time telemetry. Ocean Dyn 61(6):753-765. doi:10.1007/s10236-0110379-6
Nechad B, Alvera-Azcárate A, Ruddick K, Greenwood N (2011) Reconstruction of MODIS total suspended matter time series maps by DINEOF and validation with autonomous platform data. Ocean Dyn 61(8):1205-1214. doi:10.1007/s10236-011-0425-4

Ostrovskii A (2011) Short-term hydrophysical and biological variability over the northeastern Black Sea continental slope as inferred from multiparametric tethered profiler surveys. Ocean Dyn 61(6):797-806. doi:10.1007/s10236-011-0400-0

Petersen W, Schroeder F, Bockelmann FD (2011) FerryBox Application of continuous water quality observations along transects in the North Sea. Ocean Dyn. doi:10.1007/s10236011-0445-0

Port A, Gurgel KW, Staneva J, Schulz-Stellenfleth J, Stanev E (2011) Tidal and wind-driven surface currents in the German Bight: HFR observations versus model simulations. Ocean Dyn. doi:10.1007/s10236-011-0412-9

Schaeffer A, Molcard A, Forget P, P Fraunié PG (2011) Generation mechanisms for mesoscale eddies in the Gulf of Lions: radar observation and modeling. Ocean Dyn. doi:10.1007/s10236-011-0482-8

Uttieri M, Cianelli D, Nardelli BB, Buonocore B, Falco P, Colella S, Zambianchi E (2011) Multiplatform observation of the surface circulation in the Gulf of Naples (Southern Tyrrhenian Sea). Ocean Dyn 61(6):779-796. doi:10.1007/s10236-011-0401-z

Vousdoukas MI, Ferreira PM, Almeida LP, Dodet G, Psaros F, Andriolo U, Taborda R, Silva AN, Ruano A, Ferreira OM (2011) Performance of intertidal topography video monitoring of a meso-tidal reflective beach in South Portugal. Ocean Dyn. doi:10.1007/s10236-011-0440-5 